\title{
PENGARUH KONFLIK PERAN TERHADAP KEPUASAN KERJA MELALUI MEDIASI STRES KERJA DI KANTOR PERTANAHAN KABUPATEN GIANYAR
}

\author{
Ni Kadek Rahayu Yulianti ${ }^{1}$ \\ Made Surya Putra ${ }^{2}$ \\ Fakultas Ekonomi dan Bisnis Udayana, Bali, Indonesia \\ email:kadekrahayuy@gmail.com
}

\begin{abstract}
ABSTRAK
Tujuan penelitian adalah menganalisis pengaruh konflik peran terhadap kepuasan kerja pegawai melalui mediasi stres kerja. Penelitian bersifat asosiatif kausalitas yang dilakukan pada Kantor Pertanahan Kabupaten Gianyar melibatkan 87 responden dengan metode penentuan sampel menggunakan teknik sampel jenuh. Data dikumpulkan dengan kuesioner, dan dianalisis dengan analisis deskriptif, analisis stucturral equation modelling (SEM) berbasis PLS. Penelitian membuktikan bahwa konflik peran dan stres kerja berpengaruh negatif dan signifikan terhadap kepuasan kerja, konflik peran berpengaruh positif dan signifikan terhadap stres kerja dan stres kerja mampu memediasi pengaruh konflik peran terhadap kepuasan kerja. Penelitian membuktikan bahwa Kabupaten Gianyar perlu untuk meningkatkan kepuasan kerja pegawai khususnya dalam meningkatkan minat PPNPN mereka dalam melaksanakan pekerjaan yang di tugaskan, perlu memperhatikan cara pegawai dalam mengerjakan pekerjaan mereka, dan perlu memperhatikan komunikasi antara pegawai dan dengan atasan.
\end{abstract}

Kata kunci: kepuasan kerja, konflik peran, stres kerja

\begin{abstract}
The research objective was to analyze the effect of role conflict on employee job satisfaction through work stress mediation. This causality-associative research conducted at the Gianyar Regency Land Office involved 87 respondents with the sampling method using saturated sampling techniques. Data were collected by means of a questionnaire, and analyzed using descriptive analysis, analysis of structural equation modeling (SEM) based on PLS. Research proves that role conflict and job stress have a negative and significant effect on job satisfaction, role conflict has a positive and significant effect on job stress and job stress is able to mediate the effect of role conflict on job satisfaction. Research proves that Gianyar Regency needs to increase employee job satisfaction, especially in increasing their PPNPN interest in carrying out their assigned work, needs to pay attention to the way employees do their work, and needs to pay attention to communication between employees and superiors.
\end{abstract}

Keywords: job satisfaction, role conflict, job stress 


\section{PENDAHULUAN}

Sumber Daya Manusia (SDM) merupakan kebutuhan utama bagi perusahaan. Pentingnya sumber daya manusia bagi perusahaan, maka perlu untuk memberikan perhatian khusus terhadap sumber daya manusia mereka. Salah satu yang harus diperhatikan perusahaan adalah kepuasan kerja karyawan. Kantor Pertanahan Kabupaten Gianyar merupakan Lembaga pelayan masyarakat. Kantor Pertanahan mempunyai tugas melaksanakan sebagian tugas dan fungsi Kementerian Agraria dan Tata Ruang/Badan Pertanahan Nasional di Kabupaten/Kota yang bersangkutan. Sebagai lembaga pelayanan publik Kantor Pertanahan Kabupaten Gianyar dituntut untuk melayani permasalahan yang dihadapi masyarakat khususnya dalam bidang pertanahan.

Kantor Pertanahan Kabupaten Gianyar selalu memandang bahwa pegawai adalah sumber daya yang harus selalu dijaga dan dipelihara agar selalu memberikan pelayanan yang optimal. Kepuasan kerja pegawai merupakan salah satu hal yang diperhatikan oleh Kantor Pertanahan Kabupaten Gianyar khususnya untuk Pegawai Pemerintah Non Pegawai Negeri (PPNPN) di Kantor Pertanahan Kabupaten Gianyar. Pegawai yang merasa sangat stres pada pekerjaannya dan kurang puas dengan pekerjaannya akan mempengaruhi kinerja dari pegawai tersebut (Ranihusna et al., 2020)

\section{Tabel 1.}

Hasil Pra Survei Pegawai Pemerintah Non Pegawai Negeri (PPNPN)
\begin{tabular}{clcc} 
Kantor Pertanahan Kabupaten Gianyar & \multicolumn{1}{c}{ Pernyataan } & Ya & Tidak \\
\hline No & \multicolumn{1}{c}{ Pekerjaan yang saya terima sesuai dengan keterampilan } & 4 & 5 \\
& & 7 \\
1 & saya & 2 & 7 \\
2 & Pekerjaan yang saya terima sesuai dengan keinginan saya & 2 & 5 \\
3 & Gaji yang saya terima adil & 4 & 6 \\
4 & Gaji yang saya terima sesuai dengan harapan saya & 3 & \\
5 & Atasan saya selalu memberikan bantuan secara teknis & & 5 \\
& dalam bekerja. & 4 & 5 \\
6 & Atasan saya selalu memberikan dukungan dalam bekerja. & 4 & 3 \\
8 & Suasana di tempat kerja berjalan dengan baik & 6 & Interaksi di tempat kerja berjalan dengan baik \\
\hline
\end{tabular}

Sumber : Kuisioner pra survei (2020)

Berdasarkan Tabel 1. dapat dilihat bahwa kepuasan kerja Pegawai Pemerintah Non Pegawai Negeri (PPNPN) di Kantor Pertanahan Kabupaten Gianyar belum sesuai dengan yang diharapkan, hal ini dilihat dari lebih banyak PPNPN yang memberi jawaban tidak. Dengan melihat data wawancara ini, persepsi saya bahwa terindikasi pada permasalahan pada kepuasan kerja. Penelitian yang dilakukan Praptini, (2000) menyatakan bahwa salah satu faktor yang mempengaruhi kepuasan kerja adalah stres kerja. Sullivan \& Bhagat, (1992) menyebutkan bahwa stres kerja dapat mempengaruhi kepuasan kerja karyawan dalam suatu organisasi. Borg et al., (1991)menyatakan bahwa stres kerja adalah akibat dari peran yang berlebihan, ambiguitas peran, konflik peran, kurangnya lingkungan kerja, tuntutan lebih dari lembaga, lingkungan kerja yang tidak memadai dan hubungan yang buruk dengan rekan kerja. Konflik peran adalah pemicu yang mempengaruhi kepuasan kerja (Caplan \& Jones, 1975) Faktor yang 
menyebabkan stres kerja, salah satunya adalah konflik peran, ini memiliki dampak negatif yang signifikan terhadap kepuasan kerja (Ahsan et al., 2009).

Melalui pemaparan masalah, didukung dengan karya ilmiah dan teori tujuan dari karya ilmiah ini yang hendak dicapai 1) Untuk menjelaskan pengaruh konflik peran terhadap kepuasan kerja pegawai,2) Untuk menjelaskan pengaruh konflik peran terhadap stres kerja pegawai, 3) Untuk menjelaskan pengaruh stres kerja terhadap kepuasan kerja pegawai, 4) Untuk menjelaskan peran stres kerja dalam memediasi pengaruh konflik peran terhadap kepuasan kerja pegawai.

Kepuasan kerja dapat diartikan sebagai hal yang menyenangkan atau yang tidak menyenangkan yang mana pegawai memandang pekerjannya (Hasibuan, 2008). Spector (1997)menyatakan bahwa kepuasan kerja sebagai perasaan orang tentang pekerjaan mereka, ini menyiratkan sejauh mana kepuasan atau ketidakpuasan dalam (sejauh mana orang menyukai atau tidak menyukai) pekerjaan mereka. Davis \& Newstrom, (1996) menyatakan kepuasan kerja adalah perasaan pegawai tentang menyenangkan atau tidaknya pekerjaan yang dilakukan. Kreitner \& Knicki, (2014) menyebutkan kepuasan kerja adalah respon yang efektif atau emosional terhadap berbagai aspek pekerjaan seseorang.

Mangkunegara (2011) menyatakan bahwa terdapat dua faktor yang mempengaruhi kepuasan kerja yaitu: 1)Faktor pegawai meliputi kecerdasan IQ, umur, jenis kelamin, kecakapan kerja, kondisi fisik, tinggi rendahnya pendidikan, pengalaman kerja, kepribadian, emosional, cara berpikir, persepsi, sikap kerja, dan masa kerja, dan 2)Faktor pekerjaan meliputi struktur organisasi, pangkat dan kedudukan dalam organisasi, mutu karyawan, hubungan kerja, dan peluang promosi jabatan.

Luthans (2006) berpendapat bahwa indikator kepuasan kerja dapat dilihat dari beberapa hal yaitu : Pekerjaan itu sendiri, yaitu berkaitan dengan sejauh mana karyawan memandang pekerjaannya sebagai pekerjaan yang menarik, yang dapat memberikan kesempatan untuk menggunakan kemampuan dan ketrampilannya, Gaji, yaitu merupakan jumlah balas jasa finansial yang diterima oleh karyawan dan dipandang sebagai suatu hal yang adil dan sesuai dengan harapannya, Promosi, yaitu merupakan kesempatan karyawan untuk kenaikan jabatan dalam jenjang karir, Supervisi, yaitu merupakan kemampuan atasan untuk memberikan bantuan secara teknis maupun memberikan dukungan dalam bekerja, Rekan Kerja, yaitu terdapat pola interaksi yang terjadi dengan baik antar individu dalam suatu organisasi.

Robbins \& Judge (2015) Role Conflict adalah suatu situasi dimana individu dihadapkan oleh ekspektasi peran yang berbeda-beda. Konflik peran muncul karena banyaknya pekerjaan yang di kerjakan karyawan, (Nur et al., 2016). Kinicki \& Kreitner (2001)menyatakan bahwa ketika individu merasakan adanya tuntutan yang saling bertentangan dari orang-orang di sekitar maka individu tersebut sedang mengalami konflik peran. Konflik peran dapat dijelaskan sebagai konflik internal yang terjadi pada diri seseorang, dan akan terjadi ketika individu menghadapi suatu ketidakpastian pekerjaan yang dia harapkan untuk melakukannya, apabila berbagai permintaan pekerjaan saling bertentangan, atau bila individu diharapkan untuk melakukan lebih dari kemampuannya (Yasa, 2017).

Terdapat beberapa faktor-faktor yang mempengaruhi konflik peran menurut (Sedarmayanti.,2013) adalah sebagai berikut :1)Masalah komunikasi yang 
dikarenakan kesalahpahaman yang terjadi terkait kalimat, bahasa, atau informasi yang kurang lengkap serta gaya individu yang tidak konsisten. 2)Masalah struktur organisasi karena adanya pertarungan kekuasaan antar departemen dengan kepentingan-kepentingan atau sistem penilaian yang bertentangan, persaingan untuk memperebutkan sumber daya yang terbatas atau saling ketergantungan dua atau lebih kelompokkelompok kegiatan kerja untuk mencapai tujuan mereka. 3)Masalah pribadi yang biasanya karena merasa tidak sesuai dengan tujuan atau nilai-nilai sosial pribadi pegawai dengan perilaku yang diperankan pada jabatan mereka dan perbedaan persepsi.

Indikator-indikator dari konflik peran menurut Rizzo et al., (1970)sebagai berikut : Perbedaan cara dalam melakukan tugas, melakukan pekerjaan yang tidak perlu, perbedaan cara dalam melakukan pekerjaan meski dalam tim yang sama, melakukan pekerjaan dari dua pihak yang saling tidak bersesuaian, pelanggaran peraturan untuk dapat menyelesaikan pekerjaan, pekerjaan cenderung diterima oleh satu pihak tapi tidak dengan pihak yang lain, tidak didukung oleh sumber daya manusia yang cukup, tidak didukung oleh sumber daya dan material fisik lainnya. Dalam organisasi sangat penting memahami stres kerja karena dapat mempengaruhi sikap yang terkait dengan pekerjaan seperti kepuasan kerja, komitmen organisasi dan lain-lain (Sager, 1994).

Stres kerja adalah situasi kerja menegangkan yang mempengaruhi emosi, proses berfikir dan kondisi seseorang, (Handoko, 2012)Menurut Robbins \& Judge, (2015)stres kerja merupakan kondisi dinamis dimana seseorang individu dihadapkan dengan kesempatan, keterbatasan atau tuntutan sesuai dengan harapan dari hasil yang ingin dicapai dalam kondisi penting dan tidak menentu. Mangkunegara, (2017) mengemukakan bahwa stress kerja adalah suatu perasaan tertekan yang dialami karyawan dalam menghadapi pekerjaan.

Robbins (1998) ada tiga faktor yang dapat menyebabkan stres kerja, yaitu: 1)Faktor Lingkungan yang terdiri dari: ketidakpastian ekonomi, ketidakpastian politik, ketidakpastian teknologi ; 2)Faktor Organisasi yang terdiri dari tuntutan tugas, tuntutan peran, tuntutan antar pribadi, struktur organisasi, kepemimpinan individu, tahap organisasi; 3)Faktor Individu yang terdiri dari : masalah keluarga, masalah ekonomi, masalah kepribadian.

Indikator-indikator dari stres kerja menurut Hasibuan, (2014:204) sebagai berikut: 1)Beban kerja, diukur dari persepsi responden mengenai beban kerja yang dirasakan berlebihan. 2)Sikap pemimpin, diukur dari persepsi responden mengenai sikap pemimpin yang kurang adil dalam memberikan tugas. 3)Waktu kerja, diukur dari persepsi responden mengenai waktu kerja yang dirasakan berlebihan. 4)Konflik, diukur dari persepsi responden mengenai konflik antara karyawan dengan pimpinan. 5)Komunikasi, diukur dari persepsi responden mengenai komunikasi yang kurang baik antara karyawan. 6) Otoritas kerja, diukur dari persepsi responden mengenai otoritas kerja yang berhubungan dengan tanggung jawab. 


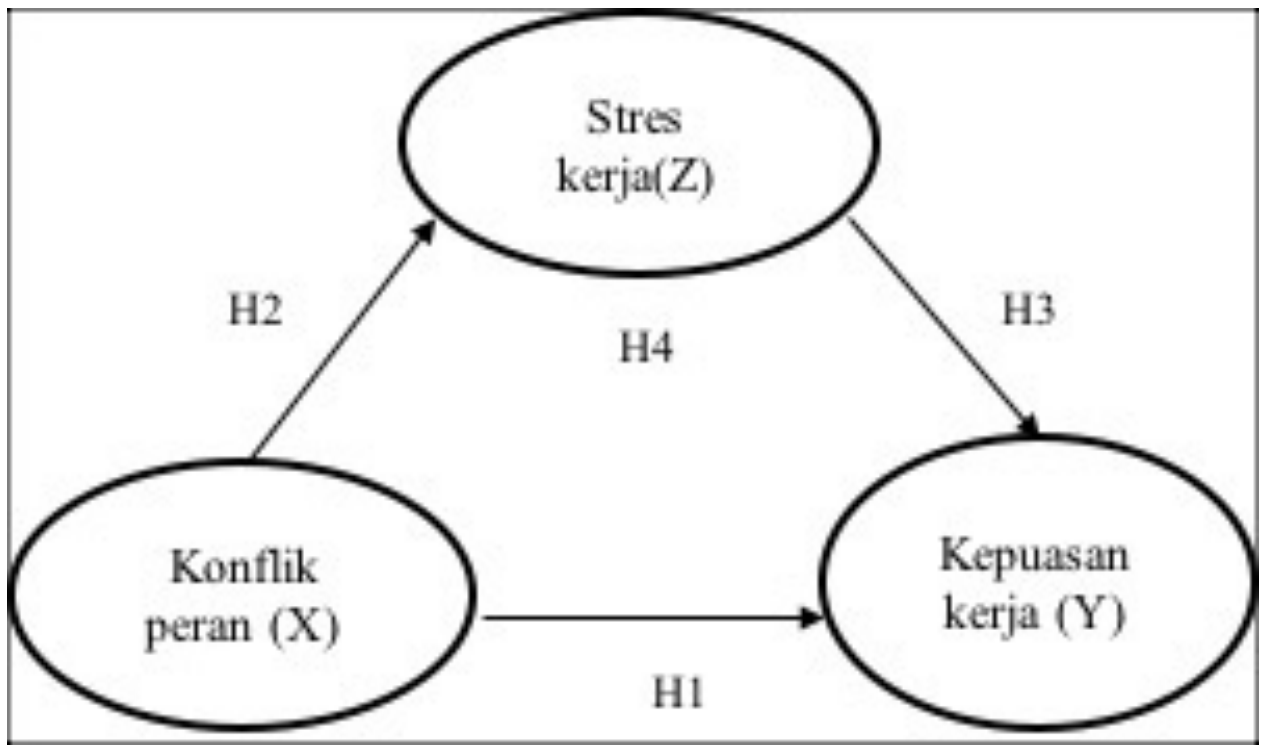

Gambar 1. Kerangka Konseptual Penelitian

Penelitian yang dilakukan oleh Akwan et al. (2016) menunjukkan bahwa konflik peran memiliki pengaruh yang negatif dan signifikan terhadap variabel kepuasan kerja. Ranihusna et al. (2020) menyatakan konflik peran memiliki pengaruh negatif dan signifikan terhadap kepuasan kerja. Hasil penelitian Bongga \& Susanty (2018), menunjukkan konflik kerja berpengaruh negatif dan signifikan terhadap kepuasan kerja karyawan, semakin tinggi tingkat konflik peran maka kepuasan kerja karyawan akan cenderung menurun. Penelitian yang dilakukan Palomino \& Frezatti (2016)menyatakan bahwa konflik peran berpengaruh negatif terhadap kepuasan kerja.

$\mathrm{H}_{1}$ : Konflik peran berpengaruh negatif dan signifikan terhadap kepuasan kerja

Konflik peran berdampak pada peningkatan stres kerja karyawan yang berarti apabila semakin sering terjadi konflik peran akan mengakibatkan meningkatnya stres kerja karyawan (Juwita \& Arintika, 2018). Penelitian terdahulu yang dilakukan oleh Yasa (2017), menunjukkan bahwa konflik peran mempunyai pengaruh positif dan tidak signifikan terhadap stres kerja. Hasil penelitian yang dilakukan Rifai et al. (2019)menunjukkan bahwa konflik peran berpengaruh positif dan signifikan terhadap stres kerja. Penelitian yang dilakukan Priya et al. (2017) menyebutkan bahwa konflik peran berpengaruh positif dan signifikan terhadap stres kerja. Ranihusna et al. (2020) menyebutkan konflik peran berpengaruh positif terhadap stres kerja karyawan.

$\mathrm{H}_{2}$ : Konflik peran berpengaruh positif dan signifikan terhadap stres kerja

Penelitian yang dilakukan oleh Uysal (2019), menyebutkan bahwa stres kerja memiliki pengaruh negatif dan signifikan terhadap kepuasan kerja, yang berarti apabila stres kerja meningkat maka akan menurunkan kepuasan kerja karyawan. Penelitian yang dilakukan Sopiah \& Sangadji (2020)menyebutkan bahwa stres kerja berpengaruh negatif dan signifikan terhadap kepuasan kerja karyawan. Sofia et al. (2019)menyebutkan bahwa stres kerja berpengaruh negatif dan signifikan terhadap kepuasan kerja karyawan. Ranihusna et al. (2020)menyatakan stres kerja berpengaruh negatif dan signifikan terhadap kepuasan kerja. 
$\mathrm{H}_{3}$ : Stres kerja berpengaruh negatif dan signifikan terhadap kepuasan kerja

Penelitian yang dilakukan oleh Ranihusna et al., (2020) menyatakan bahwa stres kerja memediasi pengaruh konflik peran terhadap kepuasan kerja. Penelitian yang dilakukan oleh Widyani \& Sugianingrat, (2015), menyatakan bahwa stres kerja memediasi pengaruh konflik peran gada dengan kepuasan kerja. Seseorang yang menerima konflik peran pada tingkat yang tinggi sebagai sumber stres akan kurang puas dengan pekerjaannya (Yousef, 2015). Faktor yang menyebabkan stres kerja, salah satunya adalah konflik peran, ini memiliki dampak negatif dan signifikan terhadap kepuasan kerja (Ahsan et al., 2009).Penelitian yang dilakukan oleh Ain et al., (2013), menyatakan bahwa stres kerja memediasi pengaruh konflik peran terhadap kepuasan kerja karyawan.

$\mathrm{H}_{4}$ : Stres kerja mampu menjadi mediasi antara konflik peran dan kepuasan kerja

\section{METODE PENELITIAN}

Pendekatan yang digunakan pada penelitian ini adalah pendekatan kuantitatif yang secara spesifik bersifat asosiatif kausalitas. penelitian ini dilakukan di Kantor Pertanahan (BPN) Kabupaten Gianyar. Objek penelitian ini adalah variabel endogen konflik peran $(\mathrm{X})$, variabel mediasi stres kerja $(\mathrm{Z})$ dan variabel eksogen kepuasan kerja (Y). Jenis data kuantitatif dalam penelitian ini adalah data jumlah karyawan serta skor jumlah kuisioner yang diangkakan. Sedangkan data kualitatif dalam penelitian ini termasuk gambaran umum perusahaan dan item pertanyaan dalam kuisioner. Sumber primer dalam penelitian ini adalah Pegawai Pemerintah Non Pegawai Negeri (PPNPN) Kantor Pertanahan Kabupaten Gianyar sebagai responden penelitian. Sumber sekunder dalam penelitian ini adalah pihak Kantor Pertanahan Kabupaten Gianyar.

Instrumen penelitian ini berbentuk kuisioner, yang terdiri dari pertanyaan terbuka dan pertanyaan tertutup dan menggunakan skala Likert. Dalam Karya Ilmiah ini uji validitas dapat dikatakan valid apabila koefisien korelasi positif dan lebih besar dari 0.03 dengan tingkat kesalahan alpha 0.05 dan uji reliabilitas instrumen dikatakan raliabel apabila koefisien Alpha Cronbach $\geq 0,6$. Populasi yang digunakan dalam penelitian ini adalah seluruh pegawai Kantor Pertanahan Kabupaten Gianyar yang merupakan Pegawai Pemerintah Non Pegawai Negeri (PPNPN) yaitu sebanyak 87 orang. Sampel dalam penelitian ini sebanyak 87 orang. Teknik pengambilan sampel dalam penelitian ini adalah teknik sampel jenuh yang memberikan peluang yang sama bagi setiap unsur populasi untuk dipilih menjadi anggota sampel. Metode pengumpulan data yang digunakan dalam penelitian ini adalah dengan wawancara dan survei. Data yang diperoleh kemudian dianalisis menggunakan statistik deskriptif dan statistik inferensial berupa analisis stucturral equation modelling (SEM). 


\section{HASIL DAN PEMBAHASAN}

Berdasarkan Tabel 2. menunjukkan bahwa sebagian besar responden pada penelitian berumur 26 sampai 30 tahun sebanyak 30 orang atau 34,4 persen. Hal ini menunjukan bahwa sebagian besar pegawai yang bekerja di Kantor Pertanahan Kabupaten Gianyar tergolong pegawai yang berusia produktif. Sedangkan karakteristik responden berdasarkan jenis kelamin menunjukkan bahwa pegawai yang bekerja pada Kantor Pertanahan Kabupaten Gianyar didominasi oleh pegawai yang berjenis kelamin laki - laki dengan jumlah 55 orang atau 63,2 persen.

Tabel 2.

Karakteristik Responden

\begin{tabular}{|c|c|c|c|}
\hline \multirow{2}{*}{ No } & \multirow{2}{*}{ Umur } & \multicolumn{2}{|c|}{ Jumlah } \\
\hline & & Orang & Persentase $(\%)$ \\
\hline 1 & 21 - 25 Tahun & 18 & 20,6 \\
\hline 2 & 26 - 30 Tahun & 30 & 34,4 \\
\hline 3 & $31-35$ Tahun & 21 & 24,1 \\
\hline 4 & $>35$ Tahun & 18 & 20,6 \\
\hline \multirow{2}{*}{ No } & \multirow{2}{*}{ Jenis Kelamin } & \multicolumn{2}{|c|}{ Jumlah } \\
\hline & & Orang & Orang \\
\hline 1 & Laki - Laki & 55 & 63,2 \\
\hline 2 & Perempuan & 32 & 36,7 \\
\hline \multirow{2}{*}{ No } & \multirow{2}{*}{ Masa Kerja } & \multicolumn{2}{|c|}{ Jumlah } \\
\hline & & Orang & Orang \\
\hline 1 & 1 - 5 Tahun & 43 & 49,4 \\
\hline 2 & 6 - 10 Tahun & 36 & 41,3 \\
\hline 3 & $>10$ Tahun & 8 & 9,1 \\
\hline \multirow{2}{*}{ No } & \multirow{2}{*}{ Pendidikan Formal } & \multicolumn{2}{|c|}{ Jumlah } \\
\hline & & Orang & Orang \\
\hline 1 & SMA & 49 & 56,3 \\
\hline 2 & Diploma & 3 & 3,4 \\
\hline 3 & Sarjana & 32 & 36,7 \\
\hline 4 & Lainnya (SD, SMP dan tidak lulus SD) & 3 & 3,4 \\
\hline
\end{tabular}

Sumber: Kantor Pertanahan Kabupaten Gianyar, 2020

Berdasarkan Tabel 2. karakteristik repsonden berdasarkan masa kerja menunjukkan bahwa karyawan di Kantor Pertanahan Kabupaten Gianyar didominasi karyawan yang sudah bekerja 1 sampai 5 tahun dengan jumlah 43 orang atau 49,4 persen. Hal ini dikarenakan Kantor Pertanahan Kabupaten Gianyar terjadwal melakukan perekrutan pegawai pemerintah non pegawai negeri sehingga pegawai pada Kantor Pertanahan Kabupaten Gianyar termasuk pegawai baru. Karakteristik responden berdasarkan pendidikan formal menunjukkan bahwa pegawai Kantor Pertanahan Kabupaten Gianyar didominasi oleh pegawai berpendidikan SMA yakni 49 orang atau 56,3 persen. 
Uji validitas dilakukan dengan mengkorelasikan antara skor faktor dengan skor total dan bila korelasi tiap faktor tersebut bernilai positif $(r>0,3)$, maka instrumen penelitian tersebut dapat dikatakan valid.

\section{Tabel 3.}

Hasil Uji Validitas Instrumen Penelitian

\begin{tabular}{|c|c|c|c|c|}
\hline No & Variabel & Instrumen & Pearson Correlation & Keterangan \\
\hline \multirow{8}{*}{1} & \multirow{8}{*}{ Kepuasan kerja $(\mathrm{Y})$} & $\mathrm{Y} 1$ & 0,896 & Valid \\
\hline & & Y2 & 0,852 & Valid \\
\hline & & Y3 & 0,862 & Valid \\
\hline & & Y4 & 0,770 & Valid \\
\hline & & Y5 & 0,856 & Valid \\
\hline & & Y6 & 0,844 & Valid \\
\hline & & Y7 & 0,796 & Valid \\
\hline & & Y8 & 0,867 & Valid \\
\hline \multirow{8}{*}{2} & \multirow{8}{*}{ Konflik Peran (X) } & $\mathrm{X} 1$ & 0,723 & Valid \\
\hline & & $\mathrm{X} 2$ & 0,886 & Valid \\
\hline & & $\mathrm{X} 3$ & 0,865 & Valid \\
\hline & & $\mathrm{X} 4$ & 0,899 & Valid \\
\hline & & $\mathrm{X} 5$ & 0,922 & Valid \\
\hline & & X6 & 0,871 & Valid \\
\hline & & $\mathrm{X} 7$ & 0,907 & Valid \\
\hline & & $\mathrm{X} 8$ & 0,901 & Valid \\
\hline \multirow{6}{*}{3} & \multirow{6}{*}{ Stres Kerja (Z) } & $\mathrm{Z1}$ & 0,653 & Valid \\
\hline & & $\mathrm{Z} 2$ & 0,854 & Valid \\
\hline & & $\mathrm{Z} 3$ & 0,869 & Valid \\
\hline & & $\mathrm{Z} 4$ & 0,886 & Valid \\
\hline & & $\mathrm{Z} 5$ & 0,855 & Valid \\
\hline & & Z6 & 0,807 & Valid \\
\hline
\end{tabular}

Sumber: Data primer (data diolah),2020

Tabel 3. menunjukkan seluruh instrumen variabel penelitian telah memenuhi syarat uji validitas dengan nilai skor total Pearson Correlation setiap instrumen memiliki nilai lebih dari 0,30 dan masing-masing instrumen memiliki nilai positif sehingga instrumen layak digunakan menjadi alat ukur variabel-variabel tersebut.

Uji reliabilitas ditunjukkan melalui skor Cronbach's Alpha yang di mana jika nilai skor tersebut berada di atas 0,60 maka instrumen tersebut dapat dikatakan reliabel.

Tabel 4.

Hasil Uji Reliabilitas Instrumen Penelitian

\begin{tabular}{llcc}
\hline No & \multicolumn{1}{c}{ Variabel } & Cronbach's Alpha & Keterangan \\
\hline 1 & Kepuasan Kerja (Y) & 0,942 & Reliabel \\
2 & Konflik Peran (X) & 0,955 & Reliabel \\
3 & Stres Kerja (Z) & 0,920 & Reliabel \\
\hline
\end{tabular}

Sumber: Data primer (data diolah),2020

Tabel 4. menunjukkan uji reliabilitas pada masing-masing variabel berada pada titik di atas 0,60 yang ditunjukkan pada hasil Cronbach's Alpha, maka dapat dikatakan seluruh instrumen telah memenuhi syarat reliabilitas sehingga dapat digunakan untuk melakukan penelitian. 
Data yang diperoleh dari penyebaran kuesioner perlu dideskripsikan untuk memberikan suatu interpretasi yang jelas pada data tersebut. Nilai rata-rata (mean) digunakan untuk mendeskripsikan hasil yang diperoleh dari instrumen penelitian.

Tabel 5.

Deskripsi Jawaban Responden Terhadap Variabel Kepuasan kerja

\begin{tabular}{|c|c|c|c|c|c|c|c|c|c|}
\hline \multirow{2}{*}{ No } & \multirow{2}{*}{ Pernyataan } & \multicolumn{5}{|c|}{ Skor Jawaban } & \multirow[t]{2}{*}{ Jumlah } & \multirow{2}{*}{$\begin{array}{l}\text { Rata- } \\
\text { rata }\end{array}$} & \multirow{2}{*}{$\begin{array}{c}\text { Interpretas } \\
\text { Makna }\end{array}$} \\
\hline & & STS & TS & $\mathbf{N}$ & $\mathbf{S}$ & SS & & & \\
\hline 1 & $\begin{array}{l}\text { Pekerjaan yang saya } \\
\text { terima sesuai dengan } \\
\text { keterampilan saya }\end{array}$ & 0 & 8 & 19 & 41 & 19 & 332 & 3,82 & Tinggi \\
\hline 2 & $\begin{array}{l}\text { Pekerjaan yang saya } \\
\text { terima sesuai dengan } \\
\text { keinginan saya }\end{array}$ & 1 & 9 & 28 & 37 & 12 & 311 & 3,57 & Tinggi \\
\hline 3 & $\begin{array}{l}\text { Gaji yang saya } \\
\text { terima adil }\end{array}$ & 0 & 8 & 26 & 35 & 18 & 324 & 3,72 & Tinggi \\
\hline 4 & $\begin{array}{l}\text { Gaji yang saya } \\
\text { terima sesuai dengan } \\
\text { harapan saya }\end{array}$ & 0 & 5 & 39 & 29 & 14 & 313 & 3,60 & Tinggi \\
\hline 5 & $\begin{array}{l}\text { Atasan saya selalu } \\
\text { memberikan bantuan } \\
\text { secara teknis dalam } \\
\text { bekerja. }\end{array}$ & 0 & 6 & 25 & 33 & 23 & 334 & 3,84 & Tinggi \\
\hline 6 & $\begin{array}{l}\text { Atasan saya selalu } \\
\text { memberikan } \\
\text { dukungan dalam } \\
\text { bekerja. }\end{array}$ & 0 & 3 & 29 & 33 & 22 & 335 & 3.85 & Tinggi \\
\hline 7 & $\begin{array}{l}\text { Suasana di tempat } \\
\text { kerja berjalan dengan } \\
\text { baik }\end{array}$ & 0 & 7 & 23 & 39 & 18 & 329 & 3.78 & Tinggi \\
\hline 8 & $\begin{array}{l}\text { Interaksi di tempat } \\
\text { kerja berjalan dengan } \\
\text { baik }\end{array}$ & 0 & 5 & 26 & 32 & 24 & 336 & 3.86 & Tinggi \\
\hline & & & & & ta-r & & & 3.76 & Tinggi \\
\hline
\end{tabular}

Sumber: Data primer (data diolah),2020

Tabel 5. mengungkapkan bahwa nilai rata - rata tertinggi jawaban responden ditunjukan pada pernyataan tentang "Interaksi di tempat kerja berjalan dengan baik" dengan nilai rata - rata sebesar 3,86 yang memiliki makna interpretasi Tinggi, ini berarti secara umum responden menganggap bahwa interaksi antar pegawai di Kantor Pertanahan Kabupaten Gianyar sudah berjalan dengan baik.. Nilai rata rata terendah yakni sebesar 3,57 pada pernyataan "Pekerjaan yang saya terima sesuai dengan keinginan saya" yang memiliki makna interpretasi Tinggi, ini berarti secara umum responden menganggap bahwa pekerjaan yang dilakukan pegawai di Kantor Pertanahan Kabupaten Gianyar sesuai dengan keinginan dan harapan mereka. 
Tabel 6.

Deskripsi Jawaban Responden Terhadap Variabel Konflik Peran

\begin{tabular}{|c|c|c|c|c|c|c|c|c|c|}
\hline \multirow{2}{*}{ No } & \multirow{2}{*}{ Pernyataan } & \multicolumn{5}{|c|}{ Skor Jawaban } & \multirow{2}{*}{ Jumlah } & \multirow{2}{*}{ Rata-rata } & \multirow{2}{*}{$\begin{array}{c}\text { Interpretasi } \\
\text { Makna }\end{array}$} \\
\hline & & STS & TS & $\mathbf{N}$ & $\mathbf{S}$ & SS & & & \\
\hline 1 & $\begin{array}{l}\text { Saya melakukan hal yang } \\
\text { seharusnya dilakukan } \\
\text { secara berbeda. }\end{array}$ & 1 & 21 & 41 & 22 & 2 & 264 & 3.03 & Cukup \\
\hline 2 & $\begin{array}{l}\text { Saya mengerjakan hal } \\
\text { yang tidak perlu. }\end{array}$ & 10 & 32 & 20 & 23 & 2 & 236 & 2.71 & Cukup \\
\hline 3 & $\begin{array}{l}\text { Saya bekerja dengan dua } \\
\text { atau lebih kelompok yang } \\
\text { beroperasi dengan sangat } \\
\text { berbeda. }\end{array}$ & 7 & 26 & 24 & 28 & 2 & 253 & 2.91 & Cukup \\
\hline 4 & $\begin{array}{l}\text { Saya menerima } \\
\text { permintaan yang tidak } \\
\text { sesuai dari dua orang atau } \\
\text { lebih. }\end{array}$ & 7 & 28 & 30 & 21 & 1 & 242 & 2.78 & Cukup \\
\hline 5 & $\begin{array}{l}\text { Saya harus melanggar } \\
\text { aturan untuk } \\
\text { melaksanakan tugas. }\end{array}$ & 15 & 28 & 20 & 21 & 3 & 230 & 2.64 & Cukup \\
\hline 6 & $\begin{array}{l}\text { Saya melakukan hal yang } \\
\text { cenderung diterima oleh } \\
\text { satu orang dan tidak } \\
\text { diterima oleh orang lain. }\end{array}$ & 9 & 28 & 31 & 17 & 2 & 236 & 2.71 & Cukup \\
\hline 7 & $\begin{array}{l}\text { Saya menerima tugas } \\
\text { tanpa sumber daya } \\
\text { manusia yang memadai } \\
\text { untuk melaksanakannya. }\end{array}$ & 12 & 26 & 23 & 26 & 0 & 237 & 2.72 & Cukup \\
\hline 8 & $\begin{array}{l}\text { Saya menerima tugas } \\
\text { tanpa material fisik yang } \\
\text { memadai untuk } \\
\text { melaksanakannya. }\end{array}$ & 12 & 22 & 24 & 28 & 1 & 245 & 2.82 & Cukup \\
\hline & & & & Rata & -rata & & & 2.79 & Cukup \\
\hline
\end{tabular}

Sumber: Data primer (data diolah),2020

Tabel 6. mengungkapkan bahwa nilai rata - rata tertinggi jawaban responden ditunjukkan pada pernyataan tentang "Saya melakukan hal yang seharusnya dilakukan secara berbeda" dengan nilai rata - rata sebesar 3.03 yang memiliki makna interpretasi Cukup, ini berarti secara umum responden menganggap bahwa mereka telah melakukan pekerjaan dengan cara pengerjaan yang salah.. Nilai rata - rata terendah yakni sebesar 2.64 pada pernyataan "Saya harus melanggar aturan untuk melaksanakan tugas" yang memiliki makna interpretasi Cukup, ini berarti secara umum responden menganggap bahwa mereka terkadang harus melanggar peraturan yang di tetapkan oleh pihak kantor untuk mengerjakan pekerjaan mereka.

Tabel 7. mengungkapkan bahwa nilai rata - rata tertinggi jawaban responden ditunjukkan pada pernyataan tentang "Terjalin komunikasi yang baik antara saya dengan atasan" dengan nilai rata - rata sebesar 3.61 yang memiliki makna interpretasi Tinggi, ini berarti secara umum responden menganggap bahwa kurangnya komunikasi antara pegawai dengan atasan mereka. Nilai rata - rata 
terendah yakni sebesar 3.13 pada pernyataan "Saya merasa diberikan tanggung jawab pekerjaan yang berlebih" yang memiliki makna interpretasi Cukup, ini berarti secara umum responden menganggap bahwa terkadang pekerjaan yang harus mereka kerjakan memiliki risiko yang tinggi.

Tabel 7.

Deskripsi Jawaban Responden Terhadap Variabel Stres Kerja

\begin{tabular}{|c|c|c|c|c|c|c|c|c|c|}
\hline \multirow{2}{*}{ No } & \multirow{2}{*}{ Pernyataan } & \multicolumn{5}{|c|}{ Skor Jawaban } & \multirow{2}{*}{ Jumlah } & \multirow{2}{*}{$\begin{array}{l}\text { Rata- } \\
\text { rata }\end{array}$} & \multirow{2}{*}{$\begin{array}{c}\text { Interpretasi } \\
\text { Makna }\end{array}$} \\
\hline & & STS & TS & $\mathbf{N}$ & $\mathbf{S}$ & SS & & & \\
\hline 1 & $\begin{array}{l}\text { Ada begitu banyak } \\
\text { pekerjaan yang } \\
\text { harus saya } \\
\text { selesaikan }\end{array}$ & 0 & 15 & 29 & 42 & 1 & 290 & 3.33 & Cukup \\
\hline 2 & $\begin{array}{l}\text { Sikap pimpinan } \\
\text { saya adil }\end{array}$ & 2 & 15 & 23 & 38 & 9 & 298 & 3.43 & Tinggi \\
\hline 3 & $\begin{array}{l}\text { Waktu yang } \\
\text { diberikan untuk } \\
\text { menyelesaikan } \\
\text { pekerjaan saya adil }\end{array}$ & 0 & 17 & 25 & 42 & 3 & 292 & 3.36 & Cukup \\
\hline 4 & $\begin{array}{l}\text { Pekerjaan saya } \\
\text { memiliki risiko } \\
\text { konflik yang tinggi }\end{array}$ & 0 & 13 & 43 & 27 & 4 & 283 & 3.25 & Cukup \\
\hline 5 & $\begin{array}{l}\text { Terjalin } \\
\text { komunikasi yang } \\
\text { baik antara saya } \\
\text { dengan atasan }\end{array}$ & 1 & 10 & 21 & 45 & 10 & 314 & 3.61 & Tinggi \\
\hline 6 & $\begin{array}{l}\text { Saya merasa } \\
\text { diberikan tanggung } \\
\text { jawab pekerjaan } \\
\text { yang berlebih }\end{array}$ & 1 & 21 & 33 & 30 & 2 & 272 & 3.13 & Cukup \\
\hline & & & & & ta-ra & & & 3.35 & Cukup \\
\hline
\end{tabular}

Sumber: Data primer (data diolah),2020

Outer model yaitu spesifikasi hubungan antara variabel laten dengan indikatornya, atau disebut dengan outer relation atau measurement model, mendefinisikan karakteristik konstruk dengan variabel manifesnya. Kriteria validitas indikator diukur dengan convergent validity, sedangkan reabilitas diukur dengan composite reability dan average variance extracted (AVE). Diagram jalur evaluasi outer model ditunjukan pada Gambar 2.

Hasil pengujian convergent validity pada Tabel 8, menunjukkan bahwa seluruh nilai outer loading indikator variabel memiliki nilai lebih besar dari 0,60 . Dengan demikian, dapat disimpulkan bahwa seluruh indikator telah memenuhi persyaratan convergent validity dan dinyatakan valid. 


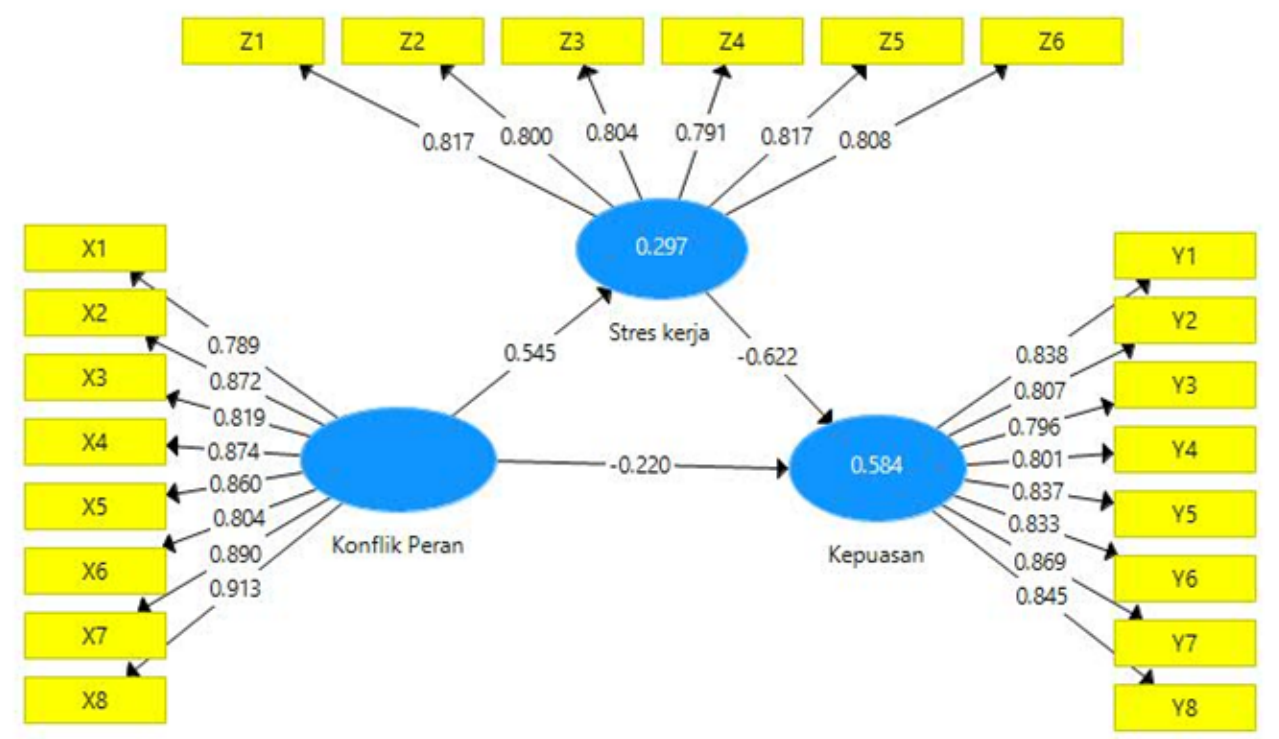

\section{Gambar 2. Diagram Jalur Model Pengukuran}

Sumber: Data primer (Data diolah),2020

Tabel 8.

Hasil Uji Validitas Convergent Validity

\begin{tabular}{|c|c|c|c|}
\hline No & Variabel & Indikator & Outer Loading \\
\hline \multirow{8}{*}{1} & \multirow{8}{*}{$\begin{array}{l}\text { Konflik } \\
\text { Peran }\end{array}$} & $\mathrm{X} 1$ & 0.789 \\
\hline & & $\mathrm{X} 2$ & 0.872 \\
\hline & & X3 & 0.819 \\
\hline & & $\mathrm{X} 4$ & 0.874 \\
\hline & & $\mathrm{X} 5$ & 0.860 \\
\hline & & X6 & 0.804 \\
\hline & & $\mathrm{X} 7$ & 0.890 \\
\hline & & $\mathrm{X} 8$ & 0.913 \\
\hline & \multirow{8}{*}{$\underset{\text { Kerja }}{\text { Kepuasan }}$} & Y1 & 0.838 \\
\hline & & Y2 & 0.807 \\
\hline & & Y3 & 0.796 \\
\hline & & Y4 & 0.801 \\
\hline & & Y5 & 0.837 \\
\hline & & Y6 & 0.833 \\
\hline & & Y7 & 0.869 \\
\hline & & Y8 & 0.845 \\
\hline & \multirow{6}{*}{ Stres Kerja } & $\mathrm{Z} 1$ & 0.817 \\
\hline & & $\mathrm{Z} 2$ & 0.800 \\
\hline & & $\mathrm{Z3}$ & 0.804 \\
\hline & & $\mathrm{Z} 4$ & 0.791 \\
\hline & & $\mathrm{Z5}$ & 0.817 \\
\hline & & Z6 & 0.808 \\
\hline
\end{tabular}

Sumber: Data primer (Data diolah),2020

Berdasarkan Tabel 9 .menjelaskan bahwa adanya discriminant validity yang sangat baik. dapat dilihat bahwa nilai cross loading setiap indikator dari variabel yang bersangkutan lebih besar dibandingkan dengan cross loading variabel lainya lebih besar dari 0,06, maka dengan demikian dapat dinyatakan bahwa data 
discriminant validity dengan menggunakan cross loading pada penelitian ini dinyatakan valid.

Tabel 9.

Hasil Uji Validitas Discriminant Validity

\begin{tabular}{lccc}
\hline & Kepuasan Kerja & Konflik Peran & Stres kerja \\
\hline $\mathrm{X} 1$ & -0.507 & 0.789 & 0.467 \\
$\mathrm{X} 2$ & -0.544 & 0.872 & 0.530 \\
$\mathrm{X} 3$ & -0.473 & 0.819 & 0.497 \\
$\mathrm{X} 4$ & -0.444 & 0.874 & 0.406 \\
$\mathrm{X} 5$ & -0.444 & 0.860 & 0.464 \\
$\mathrm{X} 6$ & -0.402 & 0.804 & 0.432 \\
$\mathrm{X} 7$ & -0.498 & 0.890 & 0.435 \\
$\mathrm{X} 8$ & -0.476 & 0.913 & 0.467 \\
\hline $\mathrm{Y} 1$ & 0.838 & -0.556 & -0.683 \\
$\mathrm{Y} 2$ & 0.807 & -0.561 & -0.591 \\
$\mathrm{Y} 3$ & 0.796 & -0.384 & -0.581 \\
$\mathrm{Y} 4$ & 0.801 & -0.431 & -0.602 \\
$\mathrm{Y} 5$ & 0.837 & -0.426 & -0.613 \\
$\mathrm{Y} 6$ & 0.833 & -0.499 & -0.593 \\
$\mathrm{Y} 7$ & 0.869 & -0.445 & -0.626 \\
$\mathrm{Y} 8$ & 0.845 & -0.377 & -0.615 \\
\hline $\mathrm{Z} 1$ & -0.605 & 0.472 & 0.817 \\
$\mathrm{Z} 2$ & -0.587 & 0.323 & 0.800 \\
$\mathrm{Z} 3$ & -0.568 & 0.458 & 0.804 \\
$\mathrm{Z} 4$ & -0.618 & 0.401 & 0.791 \\
$\mathrm{Z} 5$ & -0.584 & 0.425 & 0.817 \\
$\mathrm{Z} 6$ & -0.621 & 0.536 & 0.808 \\
\hline
\end{tabular}

Sumber : Data primer (Data dioleh), 2020

Metode lainnya untuk menilai discriminant validity yaitu dengan melihat nilai averege variance extracted (AVE), model dianggap baik jika nilai AVE masingmasing konstruk nilainya lebih besar dari 0,50. Berikut merupakan hasil uji discriminant validity dengan nilai AVE :

Tabel 10.

Hasil Average Variance Extracted

\begin{tabular}{lc}
\hline Variabel & Average Variance Extracted (AVE) \\
\hline Kepuasan Kerja & 0.687 \\
Konflik Peran & 0.728 \\
Stres kerja & 0.650 \\
Sumber : Data Primer (Data diolah),2020
\end{tabular}


Berdasarkan Tabel 10. menunjukan bahwa nilai AVE dari setiap variabel memiliki nilai AVE yang lebih besar dari 0,50, hal tersebut menyatakan bahwa Uji Validitas dengan menghitung nilai AVE dinyatakan valid.

Tabel 11.

Hasil Uji Construct Reliability

\begin{tabular}{lcc}
\hline & Composite Reliability & Cronbach's Alpha \\
\hline Kepuasan Kerja & 0.946 & 0.935 \\
Konflik Peran & 0.955 & 0.946 \\
Stres kerja & 0.918 & 0.893 \\
\hline
\end{tabular}

Sumber: Data primer (Data diolah),2020

Berdasarkan Tabel 11. hasil output dari Composite Reliability dan Cornbach Alpha baik itu dari konstruk kepuasan kerja, konflik peran dan stres kerja semuanya di atas 0,70 . Jadi, dapat disimpulkan bahwa seluruh konstruk pada penelitian ini dinyatakan reliabel.

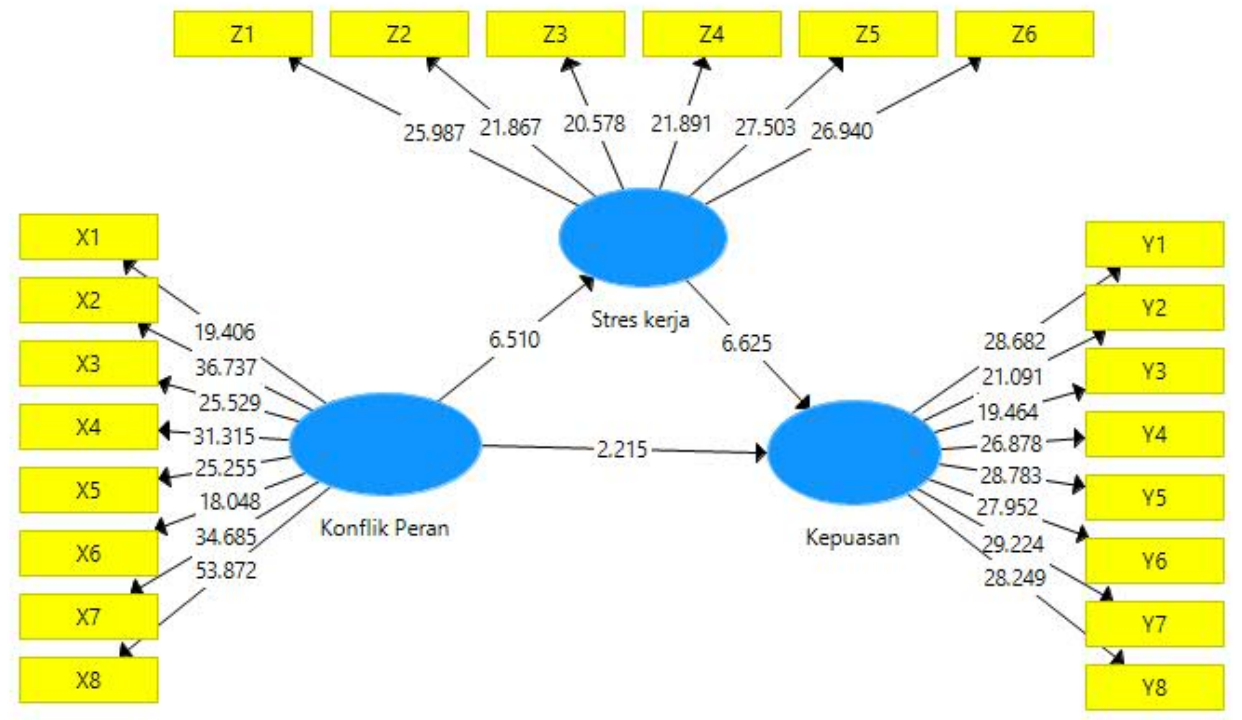

Gambar 3. Diagram Jalur Model Struktural

Sumber: Data primer (Data diolah),2020

Tabel 12.

Nilai $R$-square

\begin{tabular}{lc}
\hline \multicolumn{1}{c}{ Variabel } & R-Square \\
\hline Konflik Peran & \\
Kepuasan Kerja & 0.584 \\
Stres kerja & 0.297 \\
\hline
\end{tabular}

Sumber: Lampiran 6 Data primer (Data diolah), 2020

Tabel 12. menunjukkan nilai $R$-square untuk varibel kepuasan kerja adalah 0.584 , yang dapat diinterpretasikan sebanyak 58,4 persen konstruk kepuasan kerja dipengaruhi oleh konflik peran. Sedangkan 41,6 persen lainnya dipengaruhi oleh konstruk diluar model. Selanjutnya nilai $R$-square variabel stres kerja adalah 0.297 
persen, yang dapat diinterpretasikan sebanyak 29,7 persen konstruk stres kerja dipengaruhi oleh konflik peran dan kepuasan kerja. Sedangkan 70,3 persen lainnya dipengaruhi oleh konstruk diluar model.

Perhitungan nilai $Q$-square dapat dilihat sebagai berikut :

$$
\begin{aligned}
& \mathrm{Q}^{2}=1-\left[\left(1-\mathrm{R}^{2}\right)\left(1-\mathrm{R}^{2}\right)\right] \ldots \ldots \ldots \\
& \mathrm{Q}^{2}=1-[(1-0,584)(1-0,297)] \\
& \mathrm{Q}^{2}=1-(0,416)(0,703) \\
& \mathrm{Q}^{2}=1-0,292 \\
& \mathrm{Q}^{2}=0,708
\end{aligned}
$$

Nilai $\mathrm{Q}^{2}$ berada pada rentan $0<\mathrm{Q}^{2}<1$, dimana semakin mendekati 1 berarti model semakin baik. berdasarkan hasil perhitungan tersebut nilai $\mathrm{Q}^{2}$ yang di dapat adalah sebesar 0,708, sehingga dapat disimpulkan bahwa model memiliki predictive revelance yang baik. Dengan demikian, dapat dijelaskan bahwa 70,8 persen variabel kepuasan kerja dipengaruhi oleh variabel konflik peran dan variabel stres kerja, sedangkan 29,2 persen lainnya dipengaruhi oleh konstruk diluar model.

Pengujian terhadap hipotesis dalam metode Partial Least Square (PLS) dilakukan dengan menggunakan simulasi terhadap setiap hubungan yang dihipotesiskan dengan metode bootstrap. Metode bootstraping bertujuan untuk melihat nilai signifikansi antar variabel. Hipotesis dapat diterima apabila nilai uji bootstraping berada diantara $\pm 1,96$. Apabila nilai $t$-statistic $<1,96$ atau $=1,96$, maka hipotesis akan ditolak. Nilai t-tabel ditentukan dengan signifikansi 5 persen atau

\begin{tabular}{|c|c|c|c|c|c|}
\hline Variabel & $\begin{array}{c}\text { Original } \\
\text { Sample }(0)\end{array}$ & $\begin{array}{c}\text { Sample } \\
\text { Mean } \\
\text { (M) }\end{array}$ & $\begin{array}{l}\text { Standard } \\
\text { Deviation } \\
\text { (STDEV) }\end{array}$ & $\begin{array}{c}\text { T Statistics } \\
(\mid O / S T D E V)\end{array}$ & P Values \\
\hline $\begin{array}{l}\text { Konflik Peran }->\text { Kepuasan } \\
\text { Kerja }\end{array}$ & -0.220 & -0.223 & 0.099 & 2.215 & 0.027 \\
\hline Konflik Peran -> Stres kerja & 0.545 & 0.552 & 0.084 & 6.510 & 0.000 \\
\hline $\begin{array}{l}\text { Stres kerja }->\text { Kepuasan } \\
\text { Kerja }\end{array}$ & -0.622 & -0.622 & 0.094 & 6.625 & 0.000 \\
\hline
\end{tabular}
0,05. Semua koefisien jalur pada Tabel 13. memiliki nilai statistik di atas 1,96, sehingga dinyatakan memiliki pengaruh yang signifikan.

Tabel 13.

Path Coefficient (Mean, STDEV, T-Values, P-Values)

Sumber: Data primer (Data diolah),2020

Berdasarkan data dari Tabel 14. dapat dilihat bahwa pengaruh langsung konflik peran terhadap kepuasan kerja yaitu sebesar -0,220, pengaruh langsung konflik peran terhadap stres kerja yaitu sebesar 0,545 , pengaruh langsung stres kerja terhadap kepuasan kerja yaitu sebesar -0,622 dengan masing-masing nilai $t$ statistic sudah lebih besar dari 1,96 pan p-value lebih kecil dari 0,50 yang menunjukkan bahwa pengaruhnya adalah signifikan.

Pengaruh tidak langsung dalam penelitian ini adalah peran stres kerja memediasi pengaruh konflik peran terhadap kepuasan kerja. Besarnya pengaruh tidak langsung pada penelitian ini adalah $-0,339$, dengan $t$-statistic sebesar 4,469 dan nilai $p$-value sebesar 0,000 . Sehingga dapat disimpulkan bahwa stres kerja memediasi pengaruh konflik peran terhadap kepuasan kerja secara negatif dan 
signifikan.

Pengaruh total hubungan antara konflik peran terhadap kepuasan kerja sebesar $-0,559$ dengan $t$-statistic sebesar 7,482. Pengaruh konflik peran terhadap stres kerja sebesar 0,545 dengan t-statistic sebesar 6,510. Pengaruh stres kerja terhadap kepuasan kerja sebesar -0,622 dengan t-statistic sebesar 6,625. Masingmasing konstruk memiliki nilai p-value kurang dari 0,50. Hal ini menyatakan adanya pengaruh yang signifikan terhadap masing-maing konstruk.

\begin{tabular}{|c|c|c|c|c|}
\hline Tipe Pengaruh & Konstruk & $\begin{array}{l}\text { Standard } \\
\text { Extimates }\end{array}$ & $\begin{array}{c}\text { T Statistics } \\
(\text { O/STDEV })\end{array}$ & P Values \\
\hline \multirow{3}{*}{$\begin{array}{l}\text { Pengaruh } \\
\text { Langsung }\end{array}$} & Konflik Peran -> Kepuasan & -0.220 & 2.215 & 0.027 \\
\hline & Konflik Peran -> Stres kerja & 0.545 & 6.510 & 0.000 \\
\hline & Stres kerja -> Kepuasan & -0.622 & 6.625 & 0.000 \\
\hline \multicolumn{2}{|c|}{$\begin{array}{l}\text { Pengaruh TidakKonflik Peran -> Stres kerja -> Kepuasan } \\
\text { Langsung }\end{array}$} & -0.339 & 4.469 & 0.000 \\
\hline \multirow{2}{*}{\multicolumn{2}{|c|}{$\begin{array}{l}\text { Konflik Peran -> Kepuasan } \\
\text { Pengaruh Total Konflik Peran }->\text { Stres kerja }\end{array}$}} & -0.559 & 7.482 & 0.000 \\
\hline & & 0.545 & 6.510 & 0.000 \\
\hline & Stres kerja -> Kepuasan & -0.622 & 6.625 & 0.000 \\
\hline
\end{tabular}

Sumber: Data primer (Data diolah),2020

Estimasi model struktural yang disajikan pada Tabel 13. menunjukan bahwa pengujian $\mathrm{H}_{1}$ menjelaskan adanya pengaruh yang signifikan antara konflik peran dengan kepuasan kerja yang ditujukan nilai t-statistic sebesar $2,215(>1,96)$. Nilai koefisien jalur sebesar -0,220 yang berarti bahwa pengaruh konflik peran dengan kepuasan kerja adalah negatif, sehingga hipotesis 1 dalam penelitian ini yang menyatakan bahwa konflik peran berpengaruh negatif dan signifikan terhadap kepuasan kerja. Hasil tersebut sesuai dengan penelitian terdahulu yang pernah dilakukan oleh Akwan et al. (2016), Ranihusna et al. (2020), Bongga \& Susanty (2018), yang menyatakan bahwa konflik peran memiliki pengaruh negatif dan signifikan terhadap kepuasan kerja.

Estimasi model struktural yang disajikan pada Tabel 13 menunjukan bahwa pengujian $\mathrm{H}_{2}$ menjelaskan adanya pengaruh yang signifikan antara konflik peran dengan stres kerja yang ditujukan nilai t-statistic sebesar $6,510(>1,96)$. Nilai koefisien jalur sebesar 0,545 yang berarti bahwa pengaruh konflik peran dengan stres kerja adalah positif, sehingga hipotesis 2 dalam penelitian ini yang menyatakan bahwa konflik peran berpengaruh positif dan signifikan terhadap stres kerja. Hasil tersebut sesuai dengan penelitian terdahulu yang pernah dilakukan oleh Yasa (2017), Rifai et al. (2019) Ranihusna et al. (2020) dan Priya et al. (2017)yang menyatakan bahwa konflik peran berpengaruh positif dan signifikan terhadap stres kerja.

Estimasi model struktural yang disajikan pada Tabel 13 menunjukan bahwa pengujian $\mathrm{H}_{3}$ menjelaskan adanya pengaruh yang signifikan antara stres kerja dengan kepuasan kerja yang ditujukan nilai $t$-statistic sebesar $6.625(>1,96)$. Nilai koefisien jalur sebesar -0.622 yang berarti bahwa pengaruh stres kerja dengan kepuasan kerja adalah negatif, sehingga hipotesis 3 dalam penelitian ini yang 
menyatakan bahwa stres kerja berpengaruh negatif dan signifikan terhadap kepuasan kerja. Hasil tersebut sesuai dengan penelitian terdahulu yang pernah dilakukan oleh Uysal (2019), Hanafi \& Ulfa (2018) dan Sopiah \& Sangadji (2020) yang menyatakan bahwa stres kerja berpengarus negatif dan signifikan terhadap kepuasan kerja.

Berdasarkan data dari Tabel 1. pada pengaruh tidak langsung antara konflik peran, stres kerja dan kepuasan kerja didapatkan nilai $t$ - statistic sebesar 4,469 $(>1,96)$ dan $P$-Value sebesar $0.000(<0,050)$ yang menunjukan bahwa variabel stres kerja mampu memediasi secara parsial hubungan antara konflik peran terhadap kepuasan kerja. Hal ini telah sesuai dengan hipotesis 4 yaitu stres kerja mampu memediasi pengaruh konflik peran terhadap kepuasan kerja. Hasil tersebut sesuai dengan hasil penelitian terdahulu yang dilakukan oleh Ranihusna et al. (2020) dan Ain et al. (2013)yang menyatakan bahwa stres kerja mampu memediasi pengaruh konflik peran terhadap kepuasan kerja.

\section{SIMPULAN}

Berdasarkan hasil analisis penelitian pada bab sebelumnya maka simpulan dari penelitian ini adalah Konflik peran berpengaruh negatif dan signifikan terhadap kepuasan kerja pegawai Kantor Pertanahan Kabupaten Gianyar. Hal ini menunjukan bahwa jika konflik peran pegawai Kantor Pertanahan Kabupaten Gianyar semakin meningkat maka akan akan menurunkan kepuasan kerja pegawai Kantor Pertanahan Kabupaten Gianyar. Konflik peran berpengaruh positif dan signifikan terhadap stres kerja pegawai Kantor Pertanahan Kabupaten Gianyar. Hal ini menunjukan bahwa jika konflik peran pegawai Kantor Pertanahan Kabupaten Gianyar semakin meningkat maka akan akan meningkatkan stres kerja pegawai Kantor Pertanahan Kabupaten Gianyar. Stres kerja berpengaruh negatif dan signifikan terhadap kepuasan kerja pegawai Kantor Pertanahan Kabupaten Gianyar. Hal ini menunjukan bahwa jika stres kerja pegawai Kantor Pertanahan Kabupaten Gianyar semakin meningkat maka akan akan menurunkan kepuasan kerja pegawai Kantor Pertanahan Kabupaten Gianyar. Stres kerja memediasi pengaruh konflik peran terhadap kepuasan kerja pegawai Kantor Pertanahan Kabupaten Gianyar. Hal ini menunjukan bahwa konflik peran pegawai Kantor Pertanahan Kabupaten Gianyar memberikan dampak yang signifikan terhadap kepuasan kerja jika di mediasi oleh stres kerja.

Saran yang dapat diberikan berdasarkan hasil penelitian ini yaitu Kantor Pertanahan Kabupaten Gianyar harus lebih memperhatikan minat PPNPN dalam pekerjaan mereka. Kantor Pertanahan Kabupaten Gianyar harus menentukan cara yang tepat untuk memudahkan pegawai dalam mengerjakan pekerjaan mereka. Kantor Pertanahan Kabupaten Gianyar harus meningkatkan komunikasi antara pegawai dengan atasan.

\section{REFERENSI}

Ahsan, N., Abdullah., Z., Fie., D. ong G., \& Alam., S. S. (2009). A Study of Job Stress on Job Satisfaction among University Staff in Malaysia: Empirical Study. European Journal of Social Sciences., 8(1), 121-131. 
Ain Quarat U1, Khattak, M. A., \& Iqbal, N. (2013). Impact of Role Conflict on Job Satisfaction, Mediating Role of Job Stress in Private Banking Sector. INTERDISCIPLINARY JOURNAL OF CONTEMPORARY RESEARCH IN BUSINESS, 4(12), 711-722.

Akwan, N. M., Suprapti., N. W. S., \& Sintaasih, D. K. (2016). Terhadap Intensi Keluar ( Studi Pada Anantara Seminyak Resort \& Spa , Bali ). Jurnal Ekonomi, 12(1), 0216-2431.

Bongga, W., \& Susanty, A. I. (2018). The influence of role conflict and role ambiguity on employee job satisfaction of transportation companies in Indonesia. International Journal of Supply Chain Management, 7(2), 223227.

Borg, M. G., Riding., R. J., \& Falzon., J. M. (1991). Stress in Teaching: A Study of Occupational Stress and its Determinants, Job Satisfaction and Career Commitment among Primary Schoolteachers. Educational Psychology, 11(1), $59-75$.

Caplan, R. D., \& Jones, K. W. (1975). Effects of work load, role ambiguity, and Type A personality on anxiety, depression, and heart rate. Journal of Applied Psychology, 60(6), 713-719. https://doi.org/10.1037/0021-9010.60.6.713

Davis, K., \& Newstrom., J. W. (1996). Perilaku Dalam Organisasi (Terjemahan). Erlangga.

Hanafi, A., \& Ulfa, M. (2018). The Effect of Job Stress Toward Employee Performance Through Job Satisfaction of PT Muara Alam Sejahtera Employees. International Journal of Scientific and Research Publications, 8(8), 1-5. https://doi.org/10.29322/IJSRP.8.8.2018.p8002

Handoko, T. H. (2012). Manajemen Personalia dan Sumber Daya Manusia. BPFE.

Hasibuan, M. (2008). Manajemen Sumber Daya Manusia Perusahaan. PT. Bumi Aksa.

Hasibuan, M. (2014). Manajemen Sumber Daya Manusia. Bumi Aksara.

Juwita, K., \& Arintika, D. (2018). Dampak Konflik Peran pada Stres dan Kepuasan Kerja Karyawan IMPACT OF ROLE CONFLICT ON JOB SATISFACTION , MEDIATING JOB STRESS IN PT . JOMBANG INTERMEDIA PERS ( Jawa Pos RADAR JOMBANG ). Jurnal Konsep Bisnis Dan Manajemen, 4(2), 99-113.

Kinicki, A., \& Kreitner., R. (2001). Perilaku Organisasi. Salemba Empat.

Kreitner, R., \& Knicki., A. (2014). Organizational Behavior. Penerbit Salemba 
Empat.

Luthans, F. (2006). Organizational Behavior (10 ${ }^{\text {th }}$ Editi). Andi.

Mangkunegara, A. A. A. P. (2017). Manajemen Sumber Daya Manusia Perusahaan. PT. Remadja Rosdakarya.

Mangkunegara, A. A. P. (2011). Manajemen Sumber Daya Manusia Perusahaan. PT. Remaja Rosdakarya.

Nur, I. R., Hidayati, T., \& Maria, S. (2016). PENGARUH KONFLIK PERAN, AMBIGUITAS PERAN DAN STRES KERJA TERHADAP KINERJA KARYAWAN. Jurnal Manajemen, 8(1), 1-18.

Palomino, M. N., \& Frezatti, F. (2016). Redalyc.Role conflict, role ambiguity and job satisfaction: Perceptions of the Brazilian controllers. Revista de Administração - RAUSP, 51(2), 165-181. https://doi.org/10.5700/rausp1232

Praptini, Y. (2000). Pengaruh sumber-sumber stres kerja terhadap kepuasan kerja tenaga edukatif tetap di Universitas Airlangga Di Surabaya. In Lembaga Penelitian Universitas Airlangga (Vol. 1, Issue 1). Universitas Airlangga.

Priya, K. H., Devi, K. K., \& Sudhan, S. H. H. (2017). Examining the Effect of Role Conflict and Job Stress on Turnover Intention among the Private School Teachers in Vellore District. International Journal of Business and Management Invention, 6(1), 58-63.

Ranihusna, D., Ariani Wulansari, N., \& Karuma Asiari, D. (2020). Role Conflict Relationships That Can Increase the Satisfaction of Hospital Nurses. KnE Social Sciences, 2020(2013), 1231-1241. https://doi.org/10.18502/kss.v4i6.6673

Rifai, R. P., Saerang, D., \& Taroreh, R. (2019). Pengaruh Konflik Peran dan Ambiguitas Peran Terhadap Kinerja Karyawan dengan Stres Kerja Sebagai Variabel Intervening Pada PT. Bank SulutGo. Jurnal Riset Bisnis Dan Manajemen, 7(4), 339-350.

Rizzo, J., House., R. J., \& Lirtzman., S. I. (1970). Role Conflict and Ambiguity In Complex Organizations. Administrative Science Quarterly., 15(2), 150-163.

Robbins, S. P. (1998). Perilaku Organisasi: Konsep, Kontroversi, Aplikasi. Prenhallindo.

Robbins, S. P., \& Judge., T. A. (2015). Perilaku Organisasi (12th ed.). Salemba Empat.

Sager, J. K. (1994). A structural model depicting salespeople's job stress. Journal 
of the Academy of Marketing Science., 22(1), 74-84.

Sedarmayanti. (2013). Manajemen Sumber Daya Manusia. Refika Aditama.

Sofia, P., Dewi, A., Agung, A., \& Sriathi, A. (2019). PENGARUH STRES KERJA TERHADAP TURNOVER INTENTION YANG DIMEDIASI OLEH KEPUASAN KERJA. E-Jurnal Manajemen, 8(6), 3646-3673.

Sopiah, \& Sangadji, E. M. (2020). The Effect of Job Stress on Turnover Intention through Job Satisfaction of Government Commercial Bank Employees. KnE Social Sciences, 2020, 66-82. https://doi.org/10.18502/kss.v4i9.7317

Spector, P. E. (1997). Job Satisfaction: Application, Assessment, Causes, and Consequences. Sage Publications Ltd.

Sullivan, Sherry E., \& Bhagat, R. S. (1992). Organizational Stress, Job Satisfaction and Job Performance: Where Do We Go From Here. Journal of Management, $18(2), 235-374$.

Uysal, H. T. (2019). The Mediation Role of Toxic Leadership in the Effect of Job Stress on Job Satisfaction. INTERNATIONAL JOURNAL OF BUSINESS, 24(1), 55-73.

Widyani, A. D., \& Sugianingrat, I. W. (2015). EFFECT OF MULTIPLE ROLE CONFLICT ON JOB SATISFACTION WITH THE MEDIATION ROLE OF STRESS. International Journal of Economics, Commerce and Management, III (5), 862-872.

Yasa, I. W. M. (2017). Pengaruh Konflik Peran Dan Ambiguitas Peran Terhadap Kinerja Pegawai Melalui Mediasi Stres Kerja Pada Dinas Kesehatan Kota Denpasar Bali. Jurnal Ekonomi Dan Bisnis, 4(1), 38-57. https://doi.org/10.22225/JJ.4.1.203.38-57

Yousef, D. A. (2015). Job satisfaction as a mediator of the relationship between role stressors and organizational commitment A study from an Arabic cultural. Journal of Managerial Psychology, 17(4), 250-266. https://doi.org/10.1108/02683940210428074 